\title{
Dry Metal Forming: Definition, Chances and Challenges
}

\author{
Frank Vollertsen ${ }^{1, *}$ and Florian Schmidt \\ BIAS-Bremer Institut für angewandte Strahltechnik GmbH, Klagenfurter Str. 2, D-28359, Bremen, Germany \\ \# Corresponding Author / E-mail: vollertsen@bias.de, TEL: +49-(0)421-218-58001, FAX: +49-(0)421-218-58063
}

KEYWORDS: Dry metal forming, Avoidance of lubricants, Self-lubricating coating systems, Hard material coatings, Sustainable metal forming

\begin{abstract}
In metal forming, lubricants are still used to prevent corrosion, to reduce friction, wear and tool load as well as to protect the workpieces and intermediates. In economic and ecological points of view, the challenge is the avoidance of lubricant usage. Within this article we define the term of dry metal forming, a technology which contributes an approach to establish green technology in mass production. Regarding this, the benefits of this technology are shown. Three different approaches exist to achieve a dry forming process: ceramic tools, self-lubricating coating systems and hard material coatings. Concerning this matter, the state of research in dry metal forming is reviewed within this paper.
\end{abstract}

Manuscript received: November 22, 2013 / Accepted: December 9, 2013 (Invited Paper)

\section{Introduction}

Within the context of the United Nations Conference on Environment and Development (UNCED), the Agenda 21 was signed by 172 member states of the United Nations in 1992. As part of this action plan, the idea of sustainable use of raw materials is in the focus of research and development. The subject area production engineering has the obligation to enforce the sustainable use of all materials and resources and to develop new green technologies. To this end, resource efficiency and energy productivity are to be doubled until 2020. This includes the decrease of waste products and the abandonment of environmentally hazardous substances as well as an efficient utilization of resources.

The process of metal forming already belongs to the most energyefficient production techniques, based on the high material utilization. Currently, in all groups of procedures in metal forming, lubricants are applied to reduce friction between workpieces and forming tools, to protect semi-finished products and goods against corrosion and to reduce tool load.

However, from both an economic as well as an ecological point of view, there exists a strong demand to avoid lubricants within metal forming processes. For subsequent process steps after metal forming, such as joining and coating processes, which are susceptible to contamination and oil, it is essential to clean workpieces from lubricants. This is carried out in post-treatment processes by usage of degreasing agents which are solvent-based (mostly toxic or irritating substances) and, thus, hazardous to both environment and health.
Therefore, avoiding lubricants in metal forming would result in three significant advantages:

1. Reduction of process steps in production

2. Reduction of environmental impacts

3. Reduction of avoidable health burden

To achieve the avoidance of lubricants and to reach the vision of a lubricant-free press plant, manifold challenges on the area of metal forming, especially regarding to the field of material science have to be faced.

But first of all, the question which has to be answered is: What is the definition of dry metal forming?

Actually there is no clear definition of dry metal forming. For this reason another manufacturing technique has to be consulted to be able to determine differences and similarities.

Metal cutting without lubricants is already realized. The process of dry metal forming is defined according to the DIN 69090-1. ${ }^{1}$ The DINstandard distinguishes between conventional wet processing, minimum quantity lubrication and dry processing. Dry processes are specified within the DIN as such that can dispense with cooling lubricants. However, this distinction cannot be transferred to define dry metal forming. In the cutting process, these cooling lubricants have three functions: to reduce friction, to dissipate process heat and to flush swarf. Two functions are different, compared to those of the lubricant in metal forming processes. First, in metal forming processes there is no need to flush swarf. Second, in cold metal forming cooling of tools 
or workpieces by lubricant flush is rather rare. The lubricant has one principal function: to reduce friction within the forming process between workpiece and forming tool. Therefore, different system boundaries have to be drawn to be able to define dry metal forming compared to the cutting process.

\section{Definition of Dry Metal Forming}

The term Dry Metal Forming related to a manufacturing technique could be misinterpreted that no additives are involved within the process. This definition would be too delimiting, because this would imply that no kinds of process supporting additives are appropriate in dry metal forming. As already mentioned, in subsequent processes residues are exposed to be the essential issue in relation to the usage of lubricants. The use of additives (i.e. lubricants) should not be excluded in principle. For example, the use of volatile additives which leave no residues on workpiece or forming tool should not be excluded. In contrast, solid lubricants (also referred to as 'dry lubricants') such as molybdenum disulfides for bulk forming or polymer films on sheet metals remain on the surface after forming and can be detrimental for the further processing. Hence, solid lubricants are not compatible with the idea of dry metal forming.

Therefore to define dry metal forming it is crucial, whether a posttreatment of the workpiece is required or not. Thus we come to the conclusion that dry metal forming has to be defined as follows:

Dry metal forming is a process where a workpiece leaves the forming tool without the necessity of cleaning or drying before further production steps such as coating or joining processes.

This process chain-based definition focusses the ecological and economical points of view, i.e. avoiding any cleaning necessity after forming. In relation to preprocessing of the materials, there are no restrictions.

\section{Challenges}

The absence of a lubricant as an interlayer between workpiece and forming tool results in an intensive mechanical interaction between workpiece surface and forming tool surface. Without use of lubricant during the metal forming processes the sheet metal slides over the forming tool surface. Due to the adhesion tendency, this leads to adhesive wear between both objects. The consequence is a poor surface quality of the formed workpiece, extensive tool wear, and, as worst case, the destruction of the tool. ${ }^{2}$ This leads to large deviations from the given workpiece geometry and to additional costs for tool repairs or tool changes.

The key challenge is to influence the workpiece-tool-interaction to be able to reduce friction and wear. The influences of tribological quantities and material properties determine the boundaries of the process window in dry metal forming. With getting insights into these influences, a critical reduction of the process window can be avoided.

Focused on the forming tool, the mechanisms of tool failure are in the foreground. To control the mechanisms of failure behavior and to make dry forming applicable, an increasing load-bearing capacity of forming tools has to be realized to withstand stresses.

\section{Chances}

It can be assumed that the increased energy requirement through more complex tool manufacturing processes in dry metal forming is out of all proportion to the energy saving potential by elimination of production, transportation, application, removal and disposal of lubricants. This leads to the assumption that dry metal forming exhibits a high potential as a green technology.

Focused on the economic point of view, the cost-saving potential can be reached by dry processing amounts to about $2-17 \%$ of workpiece-specific production costs, depending on the selected production process. ${ }^{3}$ The avoidance of lubricants in metal forming enables - besides a smaller environmental impact - an increase in productivity through the reduction of work steps and the rational use of resources. Overall, an increase in sustainability compared to current process chains can be achieved.

\section{State of Research}

Dry processes in context of metal forming are researched since the 1980s. The different approaches to achieve a dry forming process can be divided into three categories (some recent work is cited in brackets, see details in the following text):

ceramic tools ${ }^{4,26,27}$

self-lubricating coating systems ${ }^{5}$

hard material coatings ${ }^{6,13-16}$

Studies on forming without lubricant have shown that the results are highly dependent on the material combinations. Forward extrusion of pure aluminum with 1.2344 tool steel could be realized under laboratory conditions. ${ }^{7}$ But the results were not transferable to workpiece materials with higher strength, such as steels. Subsequently, various coating systems were tested to counteract wear issues. This included investigations with $\mathrm{TiN},{ }^{8} \mathrm{Zr}-\mathrm{O}^{9}$ and $\mathrm{WC} \mathrm{C}^{10}$ as tool material. The wear tendency of these tools was investigated and the adhesion on forming tool was considered. ${ }^{11}$ DLC-coatings have been shown to be a promising material in dry forming. ${ }^{12}$ Within compression-spin testing, these coatings exhibit the lowest wear compared to layer systems based on BCN, WC/C-CrN, TiAlN, WC/C-TiAlN, TiC and TiN. ${ }^{13}$ DLC layers were also rated to be advantageous in wire drawing for dry processing. The operational lifespan of the layers depends significantly on the layer thickness. ${ }^{14}$

The properties of several thin-layer systems (TiCN, TiC-TiN and DLC) were investigated using press-in tests on forming tools. The adhesive wear could be minimized. Again, the DLC coatings proved to be advantageous. However, TiCN and TiC-TiN coatings exhibit a great potential for surface coating of forming tools due to their high hardness and large elastic moduli. ${ }^{15}$ Such alternatives are required, because DLC coatings do not represent the appropriate choice for all material combinations. Within a force-in test with AA6016 as workpiece 
material, DLC layers were deployed on the stamp surface. Under dry forming conditions, the DLC layer did not reduce the adhesion between workpiece and tool. ${ }^{16}$

To protect sheet metal during transport and storage, these are often processed with organic coatings. ${ }^{19}$ In forming processes these coatings also can act as a lubricant. Even in this case, DLC coatings proved to be advantageous. They have a low friction coefficient within a dry forming process with $\mathrm{Zn}$-coated steels. ${ }^{20}$ The friction coefficient is strongly influenced by the surface finish. ${ }^{21}$ In dry metal forming of rectangle aluminum workpieces a tool life of more than 5000 strokes was achieved. ${ }^{22}$ However, at a temperature of $260^{\circ} \mathrm{C}$ starts a transformation of the various bonds within the carbon based layer. ${ }^{23}$ Despite this fact, investigations with DLC, Si-DLC and $\mathrm{MoS}_{2}$ layers and multilayer systems ( $\mathrm{TiC}, \mathrm{TiN})$ where made in force-in-tests under temperature conditions up to $500^{\circ} \mathrm{C}$. The DLC-Si and DLC layers were applicable at these temperatures. ${ }^{24}$ For different workpiece materials (aluminum and steel), various a-C:H coatings proved to be suitable for dry metal forming. However, investigations in terms of tool lifetime are still required. ${ }^{25}$

Sometimes, complex workpiece coatings are used, which are addresses as dry lubricants. The tribological behavior of double (Polymer $/ \mathrm{P}+\mathrm{Mn}+\mathrm{Fe}$ ) and triple (Polymer $/ \mathrm{MoS}_{2}+\mathrm{C} / \mathrm{P}+\mathrm{Mn}+\mathrm{Fe}$ ) layers where investigated with a dry ring-on-ring test. The triple layer exhibits a lower friction coefficient and a lower wear rate. ${ }^{17}$ Investigations on friction behavior of WC/C- layers on a modified Amsler tribometer have shown a lifetime increase by a factor of $1000 .{ }^{18}$ On the other hand, those lubricants have to be removed before further processing.

Even investigations with uncoated forming tools under unlubricated conditions were made: a promising strategy is the use of ceramic tools. Different ceramic materials were used as tool material for a drawing ring within a dry deep drawing process. Depending on the workpiece material, different ceramics turn out to be promising. However, these always provide a smaller limiting drawing ratio, compared to lubricated processes. ${ }^{26}$ Another approach proved that the ceramic materials $\mathrm{ZrO}_{2}$ $\mathrm{WC}$ and $\mathrm{Al}_{2} \mathrm{O}_{3}-\mathrm{TiC}$ are suitable for dry metal forming processes. In this case, the limiting drawing ratio is close to the value within lubricated processes. $^{27}$ These investigations showed that the sensibility of tribological systems is also given in metal forming. The two investigations addressed different material combinations, leading to the reported differences.

Within further investigations, it could be shown that adhesive wear of aluminum sheets depends on the process temperature in metal forming processes with steel tools. ${ }^{28}$ Concerning this, the adhesive wear in form of cold-welding is one of the main reasons for wear of aluminum in dry metal forming with hardened steel. ${ }^{29}$

In some cases, the use of polymers as tool material can be promising. Within successful deep drawing experiments with polymer material tools under lubricated and dry conditions, it could be shown that the limiting draw ratio under dry condition is only $10 \%$ less, compared to the lubricated process. In addition, compared to the deep drawing process with steel tools, the limiting draw ratio is nearly as high as that, using a polymer tool. ${ }^{30}$

The previous research mainly focuses on laboratory investigations; moreover there is a lack of systematic studies which are applicable to high production quantities. The attempts to realize dry metal forming made in the past, referred either to systems with relatively low stresses, or failed due to the low stress resistance of the investigated multilayer systems. In meantime, further new hard material coatings and selflubricating coating systems were developed in addition to an improved understanding of surface phenomena. This leads to the assumption that it will be possible in near future to control the dry metal forming process for highly loaded systems and under conditions of mass production.

\section{Summary}

Dry metal forming is defined in this paper as: 'A process where a workpiece leaves the forming tool without the necessity of cleaning or drying before further production steps such as coating or joining processes'.

Dry metal forming contributes a new possibility to integrate green technology in mass production. This pioneering technology is a contribution to sustainable production.

Actually, no scientific work is known which proved any possibility to use dry metal forming in mass production. The previous research only investigates dry forming processes under laboratory conditions. There is need for research to answer the question concerning high production quantities.

The key to stable dry forming processes is the understanding of processes between workpiece and forming tool. There is no 'philosopher's stone', i. e. a general solution to enable a dry forming process for any combination of workpiece and forming tool materials.

\section{ACKNOWLEDGEMENT}

The work reported in this paper is funded by the German research society (DFG) within the priority program SPP 1676 Dry Metal Forming - Sustainable Production by Dry Processing in Metal Forming. The authors would like to thank the DFG for the financial support. The authors are also grateful for the support of Dr.-Ing. Z. Hu and Dipl.-Phys. M. Schwander for their valuable support in preparing the program.

\section{REFERENCES}

1. Deutsches Institut Fur Normung E.V., "MQL Processing Technology - Part 1: Terms and Definitions," GER Patent, No. DIN 69090-1, 2011.

2. Weihnacht, V., Brückner, A., and Bräunling, S., "ta-C Beschichtete Werkzeuge für die Trockenumformung von Aluminiumblechen," Vakuum in Forschung und Praxis, Vol. 20, No. 3, pp. 6-10, 2008.

3. Abele, E., Feickert, S., and Weigold, M., "Symposium zum Thema Innovative Zerspanung - Effizient und Umweltgerecht," TU Darmstadt, Inst. f. Technologie und Werkzeugmaschinen, pp. 4-6, 2004.

4. Tamaoki, K., Manabe, K., Kataoka, S., and Aizawa, T., "Electroconductive Ceramic Tooling for Dry Deep Drawing," 
Journal of Materials Processing Technology, Vol. 210, No. 1, pp. 48$53,2010$.

5. Mitsuo, A., Akhadejdamrong, T., and Aizawa, T., "Self-Lubrication of Cl-Implanted Titanium Nitride Coating for Dry Metal Forming," Materials Transactions, Vol. 44, No. 7, pp. 1295-1302, 2003.

6. Koshy, R. A., Graham, M. E., and Marks, L.D., "Temperature Activated Self-Lubrication in CrN/Mo2N N Nanolayer Coatings," Surface and Coatings Technology, Vol. 204, No. 9, pp. 1359-1365, 2010.

7. Bakhshi-Jooybari, M., "A theoretical and Experimental Study of Friction in Metal Forming by the Use of the Forward Extrusion Process," Journal of materials processing technology, Vol. 125, pp. 369-374, 2002.

8. Franklin, S. and Beuger, J., "A Comparison of the Tribological Behaviour of Several Wear-Resistant Coatings," Surface and Coatings Technology, Vol. 54, No. pp. 459-465, 1992.

9. Knotek, O., Lugscheider, E., Barimani, C., and Möller, M., "PVD Coatings for Lubricant-Free Tribological Applications," Wear, Vol. 209, No. 1-2, pp. 101-105, 1997.

10. Podgornik, B. and Hogmark, S., "Surface Modification to Improve Friction and Galling Properties of Forming Tools," Journal of Materials Processing Technology, Vol. 174, No. 1, pp. 334-341, 2006.

11. Taube, K., Grischke, M., and Bewilogua, K., "Improvement of Carbon-Based Coatings for Use in the Cold Forming of NonFerrous Metals," Surface and Coatings Technology, Vol. 68-69, pp. 662-668, 1994.

12. Hirvonen, J. P., Koskinen, J., Jervis, J. R., and Nastasi, M., "Present Progress in the Development of Low Friction Coatings," Surface and Coatings Technology, Vol. 80, No. 1-2, pp. 139-150, 1996.

13. Reisel, G., Steinhäuser, S., and Wielage, B., "The Behaviour of DLC Under High Mechanical and Thermal Load," Diamond and Related Materials, Vol. 13, No. 4-8, pp. 1516-1520, 2004.

14. Löhr, M., Spaltmann, D., Binkowski, S., Santner, E., and Woydt, M., "In situ Acoustic Emission for Wear Life Detection of DLC Coatings During Slip-Rolling Friction," Wear, Vol. 260, No. 4-5, pp. 469-478, 2006.

15. Wielage, B., Wank, A., Rupprecht, C., Schmidt, G., and Stark, S., "Schichtentwicklung für die schmiermittelfreie Umformung von hochfesten Aluminiumwerkstoffen," Materialwissenschaft und Werkstofftechnik, Vol. 39, No. 12, pp. 871-875, 2008.

16. Wank, A., Reisel, G., and Wielage, B., "Behavior of DLC Coatings in Lubricant Free Cold Massive Forming of Aluminum," Surface and Coatings Technology, Vol. 201, No. 3-4, pp. 822-827, 2006.

17. Pan, G., Guo, Q., Zhao, Z., Wang, S., Qin, Y., and Wang, L., "Tribological Properties of Solid Multilayer Composite Coatings in Dry Rolling Contact," Tribology International, Vol. 44, No. 7-8, pp.
789-796, 2011.

18. Nishimura, T., Sato, T., and Tada, Y., "Evaluation of Frictional Conditions for Various Tool Materials and Lubricants using the Injection-Upsetting Method," Journal of Materials Processing Technology, Vol. 53, No. 3-4, pp. 726-735, 1995.

19. Alsmann, M. and Behrens, B. A., "Gebrauchs- und Verarbeitungseigenschaften von Organisch Vorbeschichteten Feinblechen fur die Automobilindustrie," Tagungsband zum Industriekolloquium Fertigen in Feinblech, Clausthal-Zellerfeld, pp. 66-70, 1998.

20. Carlsson, P. and Olsson, M., "PVD Coatings for Sheet Metal Forming Processes - a Tribological Evaluation," Surface and Coatings Technology, Vol. 200, No. 14, pp. 4654-4663, 2006.

21. Osakada, K. and Matsumoto, R., "Fundamental Study of Dry Metal Forming with Coated Tools," CIRP Annals-Manufacturing Technology, Vol. 49, No. 1, pp. 161-164, 2000.

22. Murakawa, M., Koga, N., and Kumagai, T., "Deep-drawing of Aluminum Sheets without Lubricant by Use of Diamond-Like Carbon Coated Dies," Surface and Coatings Technology, Vol. 76-77, No. 2, pp. 553-558, 1995.

23. Tallant, D. R., Parmeter, J. E., Siegal, M. P., and Simpson, R. L., "The Thermal Stability of Diamond-Like Carbon," Diamond and Related Materials, Vol. 4, No. 3, pp. 191-199, 1995.

24. Reisel, G., Wielage, B., Steinhäuser, S., and Hartwig, H., "DLC for Tools Protection in Warm Massive Forming," Diamond and Related Materials, Vol. 12, No. 3-7, pp. 1024-1029, 2003.

25. Taube, K., "Carbon-based Coatings for Dry Sheet-Metal Working," Surface and Coatings Technology, Vol. 98, No. 1-3, pp. 976-984, 1998.

26. Kataoka, S., Murakawa, M., Aizawa, T., and Ike, H., "Tribology of Dry Deep-Drawing of Various Metal Sheets with Use of Ceramics Tools," Surface and Coatings Technology, Vol. 177-178, pp. 582590, 2004.

27. Tamaoki, K., Manabe, K. I., Kataoka, S., and Aizawa, T., "Electroconductive Ceramic Tooling for Dry Deep Drawing," Journal of Materials Processing Technology, Vol. 210, No. 1, pp. 48$53,2010$.

28. Groche, P. and Nitzsche, G., "Temperatureinfluss auf den Adhäsionsverschlei $\beta$ beim Umformen von Aluminiumblechen," Materialwissenschaft und Werkstofftechnik, Vol. 35, No. 7, pp. 461466, 2004.

29. Elsen, A. and Groche, P., "Adhesive Wear in Dry Sliding of Aluminum," Proc. of the 16th International Symposium on Plasticity and its Current Applications, 2010.

30. Frank, C., "Kunststoff als Werkzeugwerkstoff für das Tiefziehen von Feinblechen," Dissertation, Fachbereich Maschinenbau der Universitat Hannover, pp. 2-124, 1999. 